\title{
Underdosing of Surfactant for Preterm Babies with Respiratory Distress Syndrome in Clinical Practice: A Retrospective Cohort Study
}

\author{
Hector Boix, MD ${ }^{1}$ Segundo Rite, MD, $\mathrm{PhD}^{2}$ Luis Arruza, MD, $\mathrm{PhD}^{3} \quad$ Cristina Fernandez, $\mathrm{MD}^{1}$ \\ Itziar Serrano, $\mathrm{MD}^{2}$ Irene Baquedano, $\mathrm{MD}^{2}$ Ana Sanchez, $\mathrm{MD}^{4}$ Erika Ferreira, $\mathrm{MD}^{4}$ \\ Patricia Fernandez, MD ${ }^{3}$ Rosa Gonzalez, MD ${ }^{3}$ M. Dolores Elorza, MD, $\mathrm{PhD}^{4}$
}

\footnotetext{
${ }^{1}$ Department of Neonatology, Hospital Universitari Vall d'Hebron, Universitat Autònoma de Barcelona, Barcelona, Spain

2 Division of Neonatology, Hospital Universitario Miguel Servet, Zaragoza, Spain

${ }^{3}$ Department of Neonatology, Hospital Clínico San Carlos, Instituto de Investigación Sanitaria del Hospital Clínico San Carlos (IdISSC), Madrid, Spain

${ }^{4}$ Department of Neonatology, Hospital Universitario La Paz, Madrid, Spain
}

Am J Perinatol 2019;36:943-948.

\author{
Address for correspondence Hector Boix, MD, Department of \\ Neonatology, Hospital Universitari Vall d'Hebron, Passeig Vall \\ d'Hebron 119-129, E-08035 Barcelona, Spain \\ (e-mail: hboix@vhebron.net).
}

\begin{abstract}
Keywords

- dosage

- preterm babies

- respiratory distress syndrome

- surfactant

Objective To evaluate the initial doses of surfactant administered to preterm infants with respiratory distress syndrome.

Study Design This is a retrospective cohort study of 206 preterm infants admitted in four level III neonatal intensive care units of acute tertiary care hospitals in Spain between 2013 and 2015.

Results The mean initial dose of surfactant was $173.9(37.3) \mathrm{mg} / \mathrm{kg}$, and $47.5 \%$ of infants received a dose of $200 \mathrm{mg} / \mathrm{kg} \pm 10 \%(180-220 \mathrm{mg} / \mathrm{kg}), 47 \%$ less than $180 \mathrm{mg} /$ $\mathrm{kg}(-10 \%)$, and $5.4 \%$ more than $220 \mathrm{mg} / \mathrm{kg}(+10 \%)$. Very preterm infants ( $<28$ weeks) received higher initial doses than more mature infants, but in all cases, the mean doses were below the recommended $200 \mathrm{mg} / \mathrm{kg}$ (by $9.2 \%$ in gestational age $23-28$ weeks, by $15.9 \%$ in $29-32$ weeks, and by $24.3 \%$ in $>32$ weeks).

Conclusion Administration of surfactant below the prescribed dose is a frequent error in clinical practice. Inadvertently rounding down doses seems a plausible explanation.
\end{abstract}

Surfactant is the cornerstone of the treatment of respiratory distress syndrome (RDS) in preterm infants. Treatment with surfactant has been shown to reduce the risk of pulmonary morbidity (pneumothorax and pulmonary interstitial emphysema) and neonatal mortality. ${ }^{1-3}$ Mechanical ventilation is considered the single most important risk factor for the development of bronchopulmonary dysplasia (BPD). ${ }^{4}$ The clinical focus on avoiding mechanical ventilation and the care of infants of less than 26 weeks' gestation has spurred new approaches of surfactant administration. ${ }^{5}$

received

May 4, 2018

accepted after revision

September 25, 2018

published online

November 10, 2018
Animal-derived surfactants differ in their concentration of phospholipids and surfactant proteins, which may affect efficacy. There is evidence of the superiority of porcine (poractant alfa) versus bovine (beractant, bovactant) surfactants with respect to clinical outcomes, including mortality, the need for redosing, oxygen requirements, duration of oxygen treatment, and duration of mechanical ventilation. ${ }^{6-10} \mathrm{~A}$ survival advantage for the high dose $(200 \mathrm{mg} / \mathrm{kg})$ of poractant alfa to treat RDS as compared with the low dose $(100 \mathrm{mg} / \mathrm{kg})$ and the $100 \mathrm{mg} / \mathrm{kg} /$ dose of beractant and $50 \mathrm{mg} / \mathrm{kg} /$ dose of bovactant

Copyright $@ 2019$ by Thieme Medical Publishers, Inc., 333 Seventh Avenue, New York, NY 10001, USA. Tel: +1(212) 584-4662.
License terms

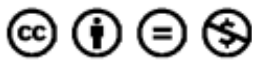

DOI https://doi.org/ 10.1055/s-0038-1675645. ISSN 0735-1631. 
has been reported. ${ }^{10}$ Also, the $100 \mathrm{mg} / \mathrm{kg} /$ dose has been shown to be an independent predictor of surfactant redosing. ${ }^{11}$ In this sense, the 2016 update of the European Consensus Guidelines on the Management of $\operatorname{RDS}^{12}$ recommends the administration of poractant alfa in an initial dose of $200 \mathrm{mg} / \mathrm{kg}$. Early surfactant administration reduces failure of continuous positive airway pressure (CPAP). ${ }^{4}$ In a population-based study, failure of CPAP for initial respiratory management in preterm infants occurred in $43 \%$ of those at $<29$ weeks' gestation and was associated with adverse outcomes including death and other major morbidities. $^{13}$ Moreover, CPAP failure usually occurs because of unremitting $\mathrm{RDS}$ and is predicted by the need of a $\mathrm{FiO}_{2} \geq 0.3$ in the first hours of life. ${ }^{14}$

Despite clinical and pharmacokinetic data supporting the dose of poractant alfa of $200 \mathrm{mg} / \mathrm{kg},{ }^{11,12,15}$ real-world studies have brought attention to the fact that the correct dose is not often given as clinicians may be tempted to administrate a rounded dose to the vial content. ${ }^{16-18}$ To further explore everyday clinical practices in neonatal intensive care units (NICUs) regarding the optimal dosing of surfactant, in an effort to ensure high standards of newborn care, a retrospective cohort study was designed. The objective of the study was to evaluate the initial dose of surfactant used in preterm infants with RDS.

\section{Materials and Methods}

\section{Study Design and Participants}

A multicenter, retrospective cohort study was performed in four level III NICUs in Spain. The primary objective of the study was to evaluate the mean initial dose of surfactant administered to preterm infants diagnosed with RDS. Secondary objectives were (1) to assess the total number of doses of surfactant, (2) to determine the percentage of patients treated with the initial dose of poractant alfa of $200 \mathrm{mg} / \mathrm{kg} \pm 10 \%$, and (3) to describe adverse events and short-term respiratory outcomes.

Between January 1, 2013, and December 31, 2015, all preterm babies (gestational age $<37$ weeks) with clinical symptoms of RDS receiving surfactant were eligible for the study. By protocol, in all four participating hospitals, the initial surfactant dose prescribed was $200 \mathrm{mg} / \mathrm{kg}$ in accordance with the recommendations of the 2013 European Consensus Guidelines on the Management of RDS. ${ }^{19}$ The availability of a minimal dataset in clinical records, including gestational age, birth weight, $\mathrm{FiO}_{2}$ before surfactant administration, and total actual dose of surfactant received in $\mathrm{mg}$ or $\mathrm{mL}$ as the initial treatment, was required for inclusion in the study. The study protocol complied with all the relevant national regulations and institutional policies, adhered to the tenets of the Declaration of Helsinki, and was approved by the Ethics Committee of Hospital Universitari Vall d'Hebron of Barcelona, Spain.

\section{Definition of Study Variables}

RDS was defined as clinical respiratory distress (tachypnea, nasal flaring, chest retractions, or grunting) that required invasive or noninvasive ventilatory support. The need for surfactant administration required $\mathrm{FiO}_{2} \geq 0.3$ to achieve $\mathrm{O}_{2}$ saturation between 90 and $95 \%$. Surfactant administration methods included intubation-surfactant-extubation(INSURE), less invasive surfactant administration (LISA), and endotracheal tube (ETT).

\section{Statistical Analysis}

According to the primary objective of the study and considering a theoretical standard deviation (SD) of 52.75 in the study population, a sample size of 167 infants was required to estimate, with a confidence interval $(\mathrm{CI})$ of $95 \%$, the mean dose of surfactant with a level of precision of $8 \mathrm{mg} / \mathrm{kg}$. The required sample size of 167 was increased to 196, assuming a percentage of $15 \%$ loss due to lack of minimal data required.

Data extracted from patients' records were entered into an electronic database for analysis. All data were anonymized. Categorical variables are expressed as frequencies and percentages, and quantitative variables as mean and $95 \%$ $\mathrm{CI}$, mean and SD, or median and interquartile range (IQR) (25th-75th percentile) as appropriate. Continuous data were compared using Student's $t$-test and the analysis of variance or the Mann-Whitney $U$ test and the Kruskal-Wallis test, and categorical data with the chi-square $\left(\chi^{2}\right)$ test or Fisher's exact test according to the distribution and size of the variables. Analyses were performed for the overall study population and for the groups categorized by gestational age between 23 and 28 weeks, between 29 and 32 weeks, and $>32$ weeks. All tests of significance were two-sided and set at $p<0.05$. The Statistical Analysis Systems software version 9.4 (SAS Institute, Cary, NC) was used for statistical analysis.

\section{Results}

A total of 219 infants was eligible during the study period, but $13(5.9 \%)$ were excluded because inclusion criteria were not met $(n=5)$ or because of lack of minimal data required $(n=8)$. Therefore, the study population included 206 infants, 116 males and 90 females, with a mean (SD) gestational age of 28.8 (3.1) weeks, mean birth weight of $1,227.3$ (582.6) $\mathrm{g}$, and median Apgar scores at 1 minute and 5 minutes of 6 (IQR 4-7) and 8 (IQR 7-9), respectively. According to gestational age, there were 120 infants in the 23- to 28 - week group, 56 in the 29- to 32-week group, and 30 in the $>32$-week group. Clinical findings before the administration of surfactant are shown in -Table 1. Antenatal corticosteroid treatment was recorded in $84 \%$ of infants. In relation to the use of ventilatory support immediately after birth in the delivery room, noninvasive ventilation was used in $49 \%$ of neonates and invasive ventilation in $41.3 \%$, and the remaining $9.7 \%$ did not require any type of ventilatory support. All patients required some type of ventilatory support during their stay in the NICU (invasive: 51.9\%; noninvasive: $48.1 \%$ ). Ventilatory failure requiring an increase in respiratory support was recorded in 42 (20.4\%) infants, with mechanical ventilation used in 27 (64.3\%) of them, mostly in infants initially treated with CPAP.

The mean $\mathrm{FiO}_{2}$ value before the administration of surfactant was 0.47 (0.18). There were no significant differences in $\mathrm{FiO}_{2}$ values according to gestational age, although higher 
Table 1 Characteristics of the study population $(n=206)$ before the administration of surfactant

\begin{tabular}{|c|c|}
\hline Variables & No. of patients (\%) \\
\hline \multicolumn{2}{|l|}{ Gender } \\
\hline Male & $116(56.3)$ \\
\hline Female & $90(43.7)$ \\
\hline Antenatal corticosteroids & $173(84)$ \\
\hline Gestational age, mean (SD) & $28.8(3.1)$ \\
\hline $23-28 w k$ & $120(58.3)$ \\
\hline $29-32$ wk & $56(27.2)$ \\
\hline$>32 \mathrm{wk}$ & $30(14.6)$ \\
\hline \multicolumn{2}{|l|}{ Delivery-related data } \\
\hline Cesarean section & $152(73.8)$ \\
\hline Singleton & $125(60.7)$ \\
\hline Multiple (twins, triplets) & $81(39.3)$ \\
\hline Premature rupture of membranes & $54(26.2)$ \\
\hline Chorioamnionitis & $25(12.1)$ \\
\hline Cord prolapse & $5(2.4)$ \\
\hline Fetal distress & $27(13.1)$ \\
\hline Presence of meconium & $5(2.4)$ \\
\hline Preeclampsia & $30(14.6)$ \\
\hline \multicolumn{2}{|l|}{ Apgar score, mean (SD) } \\
\hline $1 \mathrm{~min}$ & $6(2)$ \\
\hline $5 \mathrm{~min}$ & $8(2)$ \\
\hline Birth weight, g, mean (SD) & $1,227.3(582.6)$ \\
\hline Length, cm, mean (SD) & $37.3(5.8)$ \\
\hline \multicolumn{2}{|l|}{$\begin{array}{l}\text { Immediate ventilatory } \\
\text { support (delivery room) }\end{array}$} \\
\hline Invasive & $85(41.3)$ \\
\hline Mechanical ventilation & $85(41.3)$ \\
\hline \multicolumn{2}{|l|}{ Noninvasive } \\
\hline IPPV prongs/nasal mask & $58(28.1)$ \\
\hline SNIPPV & $2(1)$ \\
\hline CPAP & $40(19.4)$ \\
\hline Other & $1(0.5)$ \\
\hline None & $20(9.7)$ \\
\hline Ventilatory support in the NICU & $206(100)$ \\
\hline Invasive & $107(51.9)$ \\
\hline Mechanical ventilation & $107(51.9)$ \\
\hline Noninvasive & $99(48.1)$ \\
\hline IPPV & $16(7.8)$ \\
\hline CPAP & $78(37.9)$ \\
\hline BIPAP & $5(2.4)$ \\
\hline $\mathrm{O}_{2}$ saturation, $\%$, mean (SD) & $89.7(5.7)$ \\
\hline
\end{tabular}

Abbreviations: BIPAP, bilevel positive airway pressure; CPAP, continuous positive airway pressure; IPPV, intermittent positive pressure ventilation; NICU, neonatal intensive care unit; SD, standard deviation; SNIPPV, synchronized nasal intermittent positive pressure ventilation. values in infants in the $>32$-week group were found (-Table 2). The median time between birth and the administration of surfactant was 210 minutes (IQR: 60-497 minutes). The median time was significantly shorter for infants in the 23 to 28 gestational weeks as compared with those in the 29 to 32 and $>32$ weeks $(p<0.0001)$ ( - Table 2 ).

A total of $202(98.1 \%)$ infants were treated with poractant alfa and the remaining 4 (1.9\%) with beractant. Regarding the administration methods, ETT was used in $94.7 \%$ of the patients and LISA in only $5.3 \%$. In the ETT group, the INSURE method (extubating in $<1$ hour) was used in $36.4 \%$ of babies and the remaining $63.6 \%$ were extubated for $>1$ hour after surfactant administration. Extubation $>1$ hour was significantly more frequent in the 23 - to 28 -week group (74.8\%) as compared with the 29 - to 32 -week $(47.1 \%)$ and $>32$-week groups $(48.3 \%)(p=0.0005)$.

In relation to the primary objective of the study, the mean initial dose of poractant alfa was $173.9(37.3) \mathrm{mg} / \mathrm{kg}$ (median: 186.2; IQR: $149.1-200 \mathrm{mg} / \mathrm{kg}$ ). As shown in - Fig. 1, there were differences in the doses of surfactant according to gestational age, with lower doses among infants in the $>32$-week group $(p<0.001)$. A total of $47.5 \%$ of infants received an initial surfactant dose of $200 \mathrm{mg} / \mathrm{kg} \pm 10 \%(180-220 \mathrm{mg} / \mathrm{kg}), 47 \%$ received doses $<180 \mathrm{mg} / \mathrm{kg}(-10 \%)$, and $5.4 \%$ received doses $>220 \mathrm{mg} / \mathrm{kg}(+10 \%)$. Differences according to gestational age were also observed, with a significantly higher percentage of infants in the $>32$-week group treated with $<180 \mathrm{mg} / \mathrm{kg}$ as compared with the 29- to 32-week and 23- to 28-week groups $(p=0.006)(-$ Table 3$)$. Mean doses of surfactant administered according to birth weight are shown in - Fig. $\mathbf{2}$.

The need of increasing respiratory support after surfactant therapy occurred in $18.4 \%$ of patients, with mechanical ventilation, intermittent positive pressure ventilation, and synchronized nasal intermittent positive pressure ventilation being the most commonly used rescue ventilation modes.

Redosing was needed in 57 patients (59 redosings) due to persistent high oxygen requirements in $86.2 \%$ of the cases. The median time between the initial dose and the first redosing was 16.3 hours (IQR: $10.5-27$ ), and the total mean dose of surfactant retreatment was $121.2(36.9) \mathrm{mg} / \mathrm{kg}$. Need for intubation within the first 72 hours after surfactant administration was recorded in 27 (13.1\%) patients.

A total of 168 (81.6\%) patients were treated with caffeine citrate, 134 (79.8\%) of them for the prophylaxis of apnea and $33(19.6 \%)$ for the treatment of apnea.

Among all patients treated with at least one dose of surfactant, only one case of transient bradycardia (93 beats/ minute) and oxygen desaturation (82\%) possibly related to treatment was recorded.

\section{Discussion}

This study performed in routine daily practice provides evidence of administration of surfactant doses below the recommendations for treating babies with RDS. The mean first dose of poractant alfa was $173.9(37.3) \mathrm{mg} / \mathrm{kg}$, which is $13.5 \%$ lower than the theoretically prescribed and recommended dose of $200 \mathrm{mg} / \mathrm{kg}$. Interestingly, we found statistically significant 
Table $2 \mathrm{FiO}_{2}$ values and time from birth until the administration of surfactant in the overall study population and according to gestational age

\begin{tabular}{|c|c|c|c|c|c|}
\hline & \multirow{2}{*}{$\begin{array}{l}\text { All patients } \\
(n=206)\end{array}$} & \multicolumn{3}{|l|}{ Gestational age } & \multirow[t]{2}{*}{$p$-Value } \\
\hline & & $23-28$ wk $(n=120)$ & $29-32$ wk $(n=56)$ & $>32$ wk $(n=30)$ & \\
\hline \multicolumn{6}{|l|}{$\mathrm{FiO}_{2}, \%$} \\
\hline Mean (SD) & $0.47(0.18)$ & $0.47(0.18)$ & $0.44(0.18)$ & $0.52(0.21)$ & 0.137 \\
\hline Median (IQR) & $0.40(0.34-0.50)$ & $0.40(0.35-0.50)$ & $0.40(0.31-0.50)$ & $0.47(0.39-0.60)$ & \\
\hline \multicolumn{6}{|c|}{$\begin{array}{l}\text { Time from birth to use of } \\
\text { surfactant, minutes }\end{array}$} \\
\hline Mean (SD) & $416.1(566.6)$ & 219.1 (322.9) & $566.1(594.4)$ & $924.3(873.1)$ & $<0.001$ \\
\hline Median (IQR) & $210(60-497)$ & $100(30-272)$ & $301.5(196-837)$ & $669(285-144)$ & \\
\hline
\end{tabular}

Abbreviations: IQR, interquartile range; SD, standard deviation.

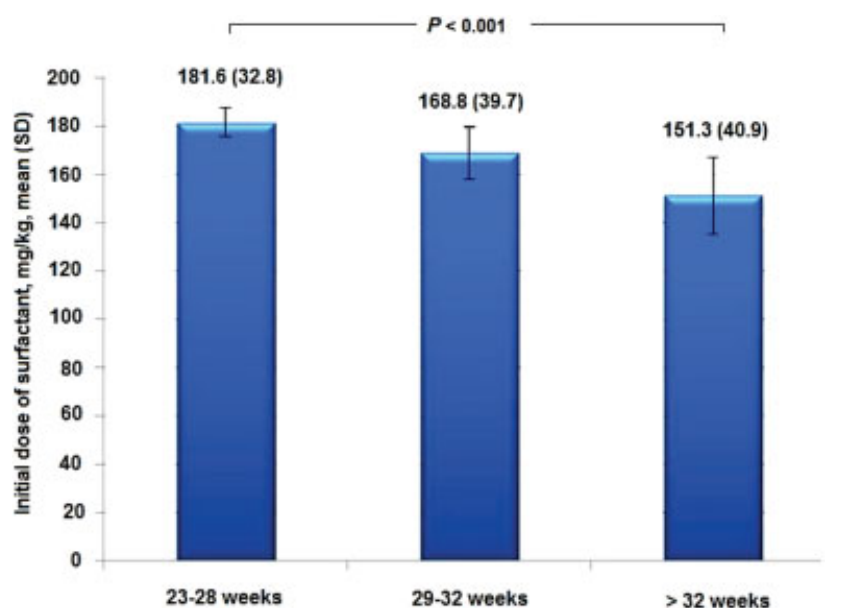

Fig. 1 Initial doses of surfactant $(\mathrm{mg} / \mathrm{kg})$ according to the gestational age.

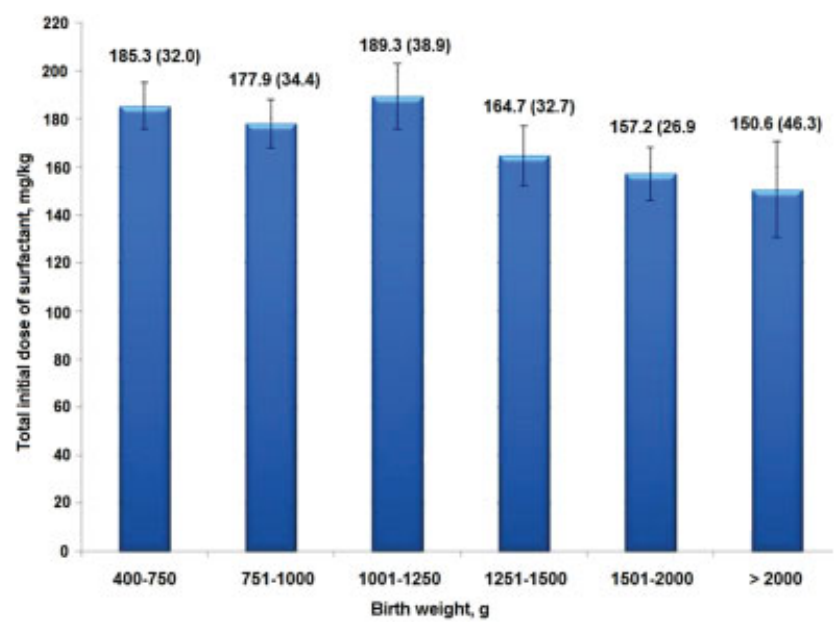

Fig. 2 Initial doses of surfactant $(\mathrm{mg} / \mathrm{kg})$ according to birth weight.

Table 3 Initial doses of surfactant in the overall study population and according to gestational age

\begin{tabular}{|c|c|c|c|c|c|}
\hline \multirow[t]{2}{*}{ Surfactant doses } & \multirow{2}{*}{$\begin{array}{l}\text { All patients } \\
(n=202)\end{array}$} & \multicolumn{3}{|l|}{ Gestational age } & \multirow[t]{2}{*}{$p$-Value } \\
\hline & & $23-28$ wk $(n=118)$ & $29-32$ wk $(n=56)$ & $>32$ wk $(n=28)$ & \\
\hline Median dose, $\mathrm{mg} / \mathrm{kg}$ & 186.2 & 190.1 & 171.1 & 166.4 & \\
\hline Target $200 \pm 10 \%, \mathrm{mg} / \mathrm{kg}$ & & & & & 0.026 \\
\hline$>220$ & $11(5.4)$ & $9(7.6)$ & $2(3.6)$ & 0 & 0.271 \\
\hline $180-220$ & $96(47.5)$ & $64(54.2)$ & $23(41.1)$ & $9(32.1)$ & 0.057 \\
\hline$<180$ & $95(47)$ & $45(38.1)$ & $31(55.4)$ & $19(67.9$ & 0.006 \\
\hline \multicolumn{6}{|l|}{ Mean (SD) dose, $\mathrm{mg} / \mathrm{kg}$} \\
\hline$>220$ & $239(22.9)$ & & & & \multirow[t]{3}{*}{$<0.001$} \\
\hline $180-220$ & $197.7(8.1)$ & & & & \\
\hline$<180$ & $142.2(27.5)$ & & & & \\
\hline
\end{tabular}

Abbreviation: SD, standard deviation.

differences in the doses of surfactant administered to patients among the three gestational age groups. In this respect, infants of lower gestational age at birth received higher initial doses of surfactant than infants of a more advanced gestational age, but in all cases, doses were below those prescribed. Extremely preterm infants ( $<28$ weeks) received a mean dose of $181.6 \mathrm{mg} / \mathrm{kg}$, which was $9.2 \%$ below the recommended dose of $200 \mathrm{mg} / \mathrm{kg}$. Infants of 29 to 32 weeks' gestational age and those $>32$ weeks' gestational age were given mean doses of 168.2 and $151.3 \mathrm{mg} / \mathrm{kg}$, respectively, which were 15.9 and 
$24.3 \%$ inferior to the target dose. A further analysis according to the distribution of initial surfactant doses by percentiles was consistent with these findings.

Globally, $47.5 \%$ of infants received doses of surfactant $<180 \mathrm{mg} / \mathrm{kg}$ (below the $\pm 10 \%$ ) and were considered to be undertreated. Considering a median dose of $186.2 \mathrm{mg} / \mathrm{kg}$, $38.1 \%$ of extremely preterm babies were undertreated $(<180$ $\mathrm{mg} / \mathrm{kg}$ ) as compared with $67.9 \%$ of moderate-late preterm babies. Also, overtreatment ( $>220 \mathrm{mg} / \mathrm{kg}$ ) was more frequent in extremely preterm than in late preterm infants $(37.6 \%$ versus $0 \%$ ). Therefore, surfactant doses above or below the recommendations showed a clear relationship with gestational age.

The problem of inappropriateness of surfactant dosing for preterm neonates with RDS has been addressed in two previous studies only, both of which have drawn attention to the urgent need of making clinicians aware of errors in surfactant administration. ${ }^{16,17}$ In a retrospective population-based cohort study of 455 infants, $25.4 \%$ were undertreated and $24.8 \%$ overtreated, with a tendency to overtreat extremely preterm and extremely low birth weight neonates and a trend to undertreat neonates $>28$ weeks' gestation, which, in turn, were more often subjected to surfactant redosing. ${ }^{16}$ In a retrospective study of 119 infants with a median gestational age of 30 weeks and birth weight of $1,300 \mathrm{~g}, 51.2 \%$ received a dose lower than $150 \mathrm{mg} / \mathrm{kg}$ (mean dose $145.8 \mathrm{mg} / \mathrm{kg}$ ), with rounding down as the most plausible explanation. ${ }^{17}$ Also, in a retrospective analysis of 987 infants with a median gestational age of 29 weeks and birth weight of $1,190 \mathrm{~g}$, the median first dose was $170 \mathrm{mg} / \mathrm{kg}$, with $79.8 \%, 19.1$, and $1.1 \%$ requiring one, two, and three doses, respectively. ${ }^{18}$ In this study, $47.5 \%$ of infants received a dose of $200 \mathrm{mg} / \mathrm{kg} \pm 10 \%$, and the dose was lower than $180 \mathrm{mg} / \mathrm{kg}$ in $47 \%$ of patients. Dose rounding due to vial optimization to minimize costs has been suggested as a possible reason for inappropriate surfactant dosing. ${ }^{16,17}$ In a European survey of surfactant replacement therapy in 338 preterm infants with a median gestational age of 27 weeks and birth weight of $860 \mathrm{~g}$, the median first dose of poractant alfa was $168 \mathrm{mg} / \mathrm{kg}^{20}$ Moreover, in a Polish survey of 987 infants from 53 NICUs, the median first dose was $170 \mathrm{mg} / \mathrm{kg},{ }^{18}$ also lower than the recommended $200 \mathrm{mg} / \mathrm{kg}$ dose.

In our study, when total mean doses were compared in the different birth weight groups, greater decreases were observed in the 1,251 to $1,500,1,501$ to 2,000 , and $>2,000$ g groups for which more than one vial content of poractant alfa (Curosurf) should be used since the product is presented in $1.5-$ or $3-\mathrm{mL}$ vials. However, the fact that $54.2 \%$ of neonates in the 23 - to 28 week group received a dose of $200 \mathrm{mg} / \mathrm{kg} \pm 10 \%$ as compared with $41.1 \%$ in the 29 - to 32 -week group and $32.1 \%$ in the $>32$ week group may also reflect greater concern for the clinical care of very premature infants. On the other hand, the time elapsed from birth to the administration of surfactant was significantly shorter in the 22- to 28 -week group than in older infants. In a randomized, masked comparison trial of preterm infants $(n=293)$ with RDS treated with an initial dose of either $100(n=96)$ or $200(n=99) \mathrm{mg} / \mathrm{kg}$ of poractant alfa or $100(n=98) \mathrm{mg} / \mathrm{kg}$ of beractant, need of redosing was significantly lower in infants treated with an initial dose of 200 $\mathrm{mg} / \mathrm{kg} .{ }^{6}$ Other outcomes including mortality up to 36 weeks in neonates born at $\leq 32$ weeks were also significantly lower in the $200 \mathrm{mg} / \mathrm{kg}$ group as compared with $100 \mathrm{mg} / \mathrm{kg}$ of poractant alfa or $100 \mathrm{mg} / \mathrm{kg}$ of beractant. ${ }^{6}$ Moreover, in a systematic review and meta-analysis of five randomized controlled trials involving 529 infants in which poractant alfa versus beractant for rescue treatment was compared, infants treated with poractant alfa at $100 \mathrm{mg} / \mathrm{kg}$ (low dose) or $200 \mathrm{mg} / \mathrm{kg}$ (high dose) exhibited statistically significant reductions in deaths, the need for redosing, oxygen requirements, duration of oxygen treatment, and duration of mechanical ventilation. ${ }^{21}$ Further studies are needed to determine if treatment with surfactant doses below the recommendations, as seen in our study, is associated with worse respiratory outcomes.

A relevant finding of this study was an actual $\mathrm{FiO}_{2}$ mean value of 0.47 before surfactant therapy, surprisingly higher than the recommended $\mathrm{FiO}_{2}$ threshold level of 0.30 to 0.40 depending on gestational age. ${ }^{12}$ Differences in $\mathrm{FiO}_{2}$ values according to gestational age were observed, with higher levels in the $>32$-week group, although differences were not statistically significant. Also, CPAP was the most frequent noninvasive ventilation method (78.8\%). However, noninvasive ventilation was associated with a higher percentage of ventilatory failure. In these cases, mechanical ventilation was the rescue ventilatory support most frequently used when CPAP failed and intubation within 72 hours of birth was required. In a study of CPAP failure in Australian and New Zealand Neonatal Network data from 2007 to 2013 in a cohort of 11,684 babies initially managed on CPAP only, failure was recorded in $43 \%$ of infants commencing on CPAP at 25 to 28 weeks' gestation and in $21 \%$ at 29 to 32 weeks. ${ }^{13}$ CPAP failure was associated with a substantially higher rate of pneumothorax, and a heightened risk of death, BPD, and other morbidities compared with those managed successfully on CPAP. ${ }^{13}$

Results of this study should be interpreted taking into account some limitations, including variability of clinical practice among the participating NICUs, the retrospective design of the study based on data collected from medical records, and results obtained for the use of poractant alfa. Poractant alfa is the most common surfactant in Europe and was the main compound used and analyzed in this study.

In conclusion, underdosing of poractant alfa is an apparently inadvertent error in surfactant administration at the bedside. Preterm babies diagnosed with RDS requiring surfactant therapy may be at a risk of undertreatment. Specific actions to avoid unintentional underdosage of surfactant are urgently needed.

\section{Authors' Contributions}

The principal investigator $H$. B. had full access to the data in the study and takes responsibility for the integrity and accuracy of the data analysis. $H$. B. was responsible for the original conception and design of the study and drafted the final version of the manuscript. Coauthors S. R., M. D. E., and L. A. assisted in the implementation of the project, critical review of the manuscript at each step, and all data analysis, and participated in the manuscript approval of the final draft. 


\section{Funding}

This study was supported by Chiesi España, S.A.U., Barcelona, Spain. Chiesi España, S.A.U. was not involved in the collection and interpretation of data, as well as writing of the manuscript.

\section{Conflict of Interest}

H.B. is a consultant of Chiesi España, S.A.U. L.A. has participated as a speaker in clinical workshops sponsored by Chiesi España, S.A.U. The remaining authors have no conflicts of interest to be disclosed.

\section{Acknowledgment}

The authors thank Marta Pulido, MD, PhD, for editing the manuscript and editorial assistance.

\section{References}

1 Zhang L, Cao HY, Zhao S, et al. Effect of exogenous pulmonary surfactants on mortality rate in neonatal respiratory distress syndrome: A network meta-analysis of randomized controlled trials. Pulm Pharmacol Ther 2015;34:46-54

2 Polin RA, Carlo WA; Committee on Fetus and Newborn; American Academy of Pediatrics. Surfactant replacement therapy for preterm and term neonates with respiratory distress. Pediatrics 2014;133(01):156-163

3 Sankar MJ, Gupta N, Jain K, Agarwal R, Paul VK. Efficacy and safety of surfactant replacement therapy for preterm neonates with respiratory distress syndrome in low- and middle-income countries: a systematic review. J Perinatol 2016;36(Suppl 1):S36-S48

4 Bohlin K, Gudmundsdottir T, Katz-Salamon M, Jonsson B, Blennow M. Implementation of surfactant treatment during continuous positive airway pressure. J Perinatol 2007;27(07):422-427

5 Niemarkt HJ, Hütten MC, Kramer BW. Surfactant for respiratory distress syndrome: new ideas on a familiar drug with innovative applications. Neonatology 2017;111(04):408-414

6 Ramanathan R, Rasmussen MR, Gerstmann DR, Finer N, Sekar K; North American Study Group. A randomized, multicenter masked comparison trial of poractant alfa (Curosurf) versus beractant (Survanta) in the treatment of respiratory distress syndrome in preterm infants. Am J Perinatol 2004;21(03):109-119

7 Ramanathan R, Bhatia JJ, Sekar K, Ernst FR. Mortality in preterm infants with respiratory distress syndrome treated with poractant alfa, calfactant or beractant: a retrospective study. J Perinatol 2013; 33(02):119-125
8 Fujii AM, Patel SM, Allen R, Doros G, Guo CY, Testa S. Poractant alfa and beractant treatment of very premature infants with respiratory distress syndrome. J Perinatol 2010;30(10):665-670

9 Dizdar EA, Sari FN, Aydemir C, et al. A randomized, controlled trial of poractant alfa versus beractant in the treatment of preterm infants with respiratory distress syndrome. Am J Perinatol 2012; 29(02):95-100

10 Singh N, Halliday HL, Stevens TP, Suresh G, Soll R, Rojas-Reyes MX. Comparison of animal-derived surfactants for the prevention and treatment of respiratory distress syndrome in preterm infants. Cochrane Database Syst Rev 2015;(12):CD010249

11 Cogo PE, Facco M, Simonato M, et al. Pharmacokinetics and clinical predictors of surfactant redosing in respiratory distress syndrome. Intensive Care Med 2011;37(03):510-517

12 Sweet DG, Carnielli V, Greisen G, et al. European Consensus Guidelines on the Management of Respiratory Distress Syndrome - 2016 Update. Neonatology 2017;111(02):107-125

13 Dargaville PA, Gerber A, Johansson S, et al; Australian and New Zealand Neonatal Network. Incidence and outcome of CPAP failure in preterm infants. Pediatrics 2016;138(01):e20153985

14 Dargaville PA, Aiyappan A, De Paoli AG, et al. Continuous positive airway pressure failure in preterm infants: incidence, predictors and consequences. Neonatology 2013;104(01):8-14

15 Cogo PE, Facco M, Simonato M, et al. Dosing of porcine surfactant: effect on kinetics and gas exchange in respiratory distress syndrome. Pediatrics 2009;124(05):e950-e957

16 Jourdain G, Zacaria F, Ammar F, De Luca D. Appropriateness of surfactant dosing for preterm babies with respiratory distress syndrome: retrospective cohort study. Arch Dis Child Fetal Neonatal Ed 2016;101(02):F182-F183

17 Boix H, Fernández C, Castillo F. Surfactant doses: From words to action . [in Spanish]. An Pediatr (Barc) 2016;85(01):55-56

18 Borszewska-Kornacka MK, Kostuch M, Korbal P, Krajewski P; Polish RDS Study Group. Strategies of using surfactant: results of the first Polish national survey of daily practice. Dev Period Med 2015;19(3 Pt 1):271-276

19 Sweet DG, Carnielli V, Greisen G, et al; European Association of Perinatal Medicine. European consensus guidelines on the management of neonatal respiratory distress syndrome in preterm infants-2013 update. Neonatology 2013;103(04):353-368

20 van Kaam AH, De Jaegere AP, Borensztajn D, Rimensberger PC; Neovent Study Group. Surfactant replacement therapy in preterm infants: a European survey. Neonatology 2011;100(01): 71-77

21 Singh N, Hawley KL, Viswanathan K. Efficacy of porcine versus bovine surfactants for preterm newborns with respiratory distress syndrome: systematic review and meta-analysis. Pediatrics 2011;128(06):e1588-e1595 